\title{
Proyecto Nuraghe: soluciones en tiempo de crisis. Un proyecto arqueológico colaborativo y socio-científico
}

En la edición anterior de la revista $\mathrm{PH}$, dos interesantes publicaciones planteaban problemas en torno al patrimonio cultural. Susana Muñoz exponía el mantenimiento del patrimonio en tiempo de crisis y las dificultades de financiación para su investigación, conservación, restauración y protección. Álvaro Álvarez analizaba la problemática existente ante la "obligación social" de difundir el patrimonio. Estos importantes obstáculos pueden terminar siendo insalvables en la coyuntura actual, teniendo como resultado el alejamiento de las instituciones y la sociedad de su propia riqueza y huella cultural. El proyecto Nuraghe nace como respuesta a dicha problemática y por ello apuesta por un nuevo modelo, cuyo pilar fundamental es la acción social, abriendo nuevas vías para la financiación y difusión con propuestas alternativas a los planteamientos tradicionales. Se trata de un nuevo enfoque socio-científico basado en la implicación de la población local y el empleo de su patrimonio como recurso de acción. Somos una iniciativa comunitaria que surge como herramienta de experimentación para la búsqueda de soluciones innovadoras.

\section{Araceli Rodríguez Azogue, Ana Gómez Díaz, Manuela Puddu | miembros del Proyecto Nuraghe}

URL de la contribución <www.iaph.es/revistaph/index.php/revistaph/article/view/3660>

San Giovanni Suergiu ${ }^{1}$ es un pequeño municipio de 6.000 habitantes, situado al suroeste de Cerdeña, en la provincia de Sulcis-Iglesiente, poseedor de un gran patrimonio histórico-arqueológico. Las prospecciones llevadas a cabo por el proyecto de investigación de la Universidad de Sevilla In campis myrtei así lo pusieron de manifiesto en 2012.

El interés y potencialidad de algunos de los yacimientos localizados, entre los que destaca Candelargiu, unido al enorme activismo social del municipio en pos de la recuperación y puesta en valor de su patrimonio cultural, fueron los principales motivos que originaron el proyecto Nuraghe.

Se trata de un asentamiento nurágico, descubierto en el año 2009 que, aún a pesar de su gran interés patrimonial y de su monumentalidad, no había sido aún investigado. La cultura nurágica (1800 a. de C.) debe su nombre a los nuraghes, peculiares torres-fortalezas surgidas de la evolución de los megalitos de la cultura preexistente. La torre nurágica es considerada por la comunidad científica como el monumento megalítico más grande y mejor conservado de Europa. Este reconocimiento hizo que se convirtiera en uno de los símbolos más destacados de
Cerdeña funcionando como un elemento de identidad que cohesiona a la cultura sarda en su pasado único y común.

En el Nuraghe Candelargiu, de gran relevancia en la comarca, debido a su extensión, complejidad y conservación, encontramos: el nuraghe, construcción monumental de marcado carácter simbólico y compuesto de tres torres; la gran cabaña de reunión, edificio de planta circular en el que se congregaban las personas más importantes de la comunidad, y el villaggio o poblado, formado fundamentalmente por cabañas de piedra en las que habitaba la población².

Las asociaciones culturales de San Giovanni, conscientes de la potencialidad del yacimiento, emprendieron diversas acciones con el objetivo de concienciar al resto de la población y a las administraciones públicas de su valor. Sus esfuerzos se vieron recompensados con el inicio de los trámites para dotar al yacimiento de la máxima figura de protección administrativa y la gestión municipal de su parcela.

En este contexto, nos encontramos con una gran implicación por parte de la comunidad y con una administración 


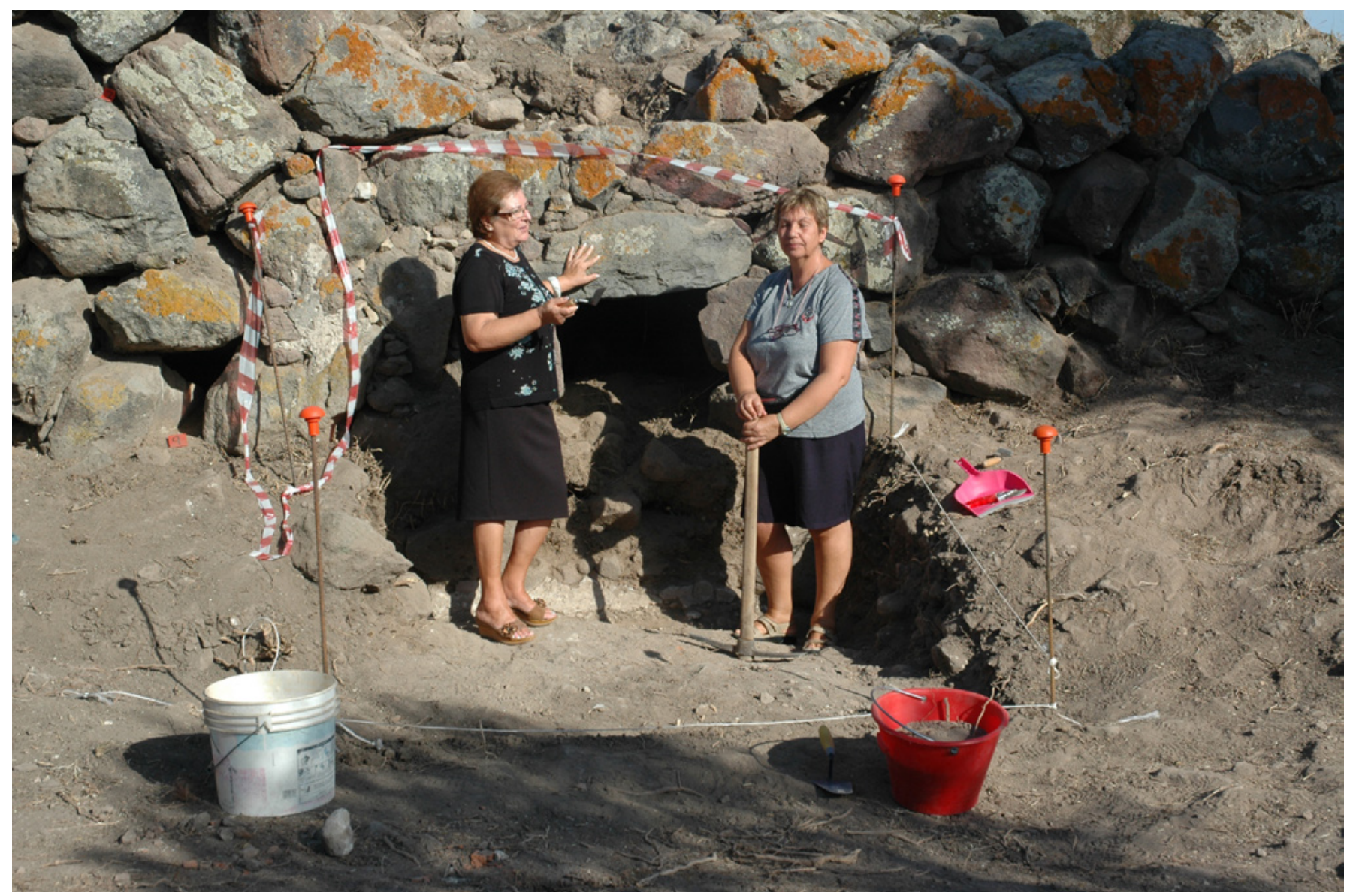

Colaboradoras del proyecto Nuraghe | foto proyecto Nuraghe

que había dado los primeros pasos para su protección, pero con la enorme dificultad por ambas partes de afrontar su estudio y su puesta en valor, al carecer de los medios para llevarlo a cabo; a esto se ha de añadir la situación de crisis económica y social que azota especialmente a las regiones mediterráneas.

El gran interés arqueológico que suscita el descubrimiento de un patrimonio oculto unido a la ilusionante disposición de la población local por investigar su pasado nos planteó un reto: ¿Cómo poder integrar ambas aspiraciones de manera solidaria? En el 2013 nace como respuesta el proyecto Nuraghe.

Momentos de crisis como el actual hacen que nos replanteemos escenarios que tradicionalmente funcionaban gracias a las políticas y usos establecidos dependientes de las subvenciones públicas. Esta coyuntura ha puesto en evidencia la frágil situación de los sitios arqueológicos, ya que todo el trabajo que giraba en torno a ellos se ha visto mermado, e incluso ha desaparecido, al suprimirse las aportaciones económicas que permitían su supervivencia, llevándolos al abandono.

La sociedad es consciente del deterioro de su patrimonio y son cada vez más las voces que abogan por la recuperación y mantenimiento de estos lugares de interés cultural. Sin embargo, la falta de herramientas que permitan su sostén mediante canales de financiación alternativos, unida a la controversia socio-científica que plantea la utilidad social de estos bienes, los sitúa a la cola de las cuestiones prioritarias a solventar desde la administración, agudizando la precariedad de su situación. 


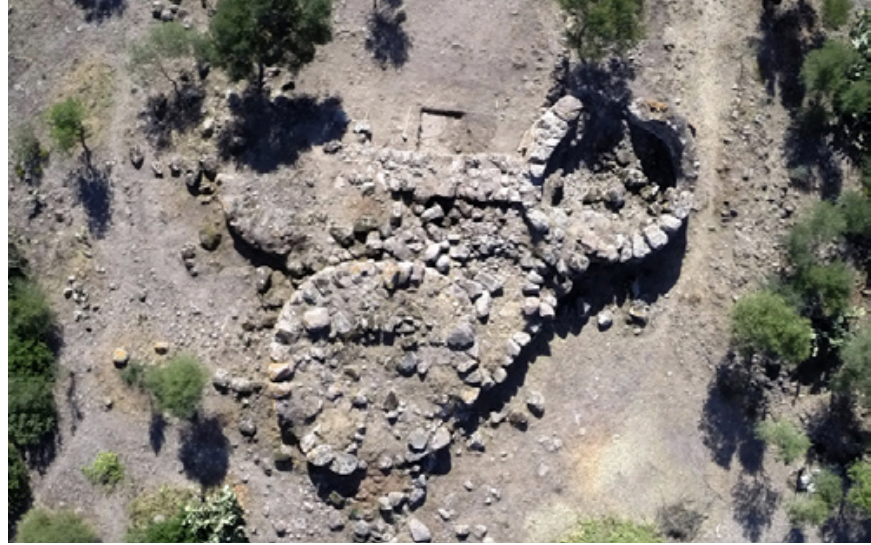

Foto aérea del nuraghe | foto Nicola Castangia

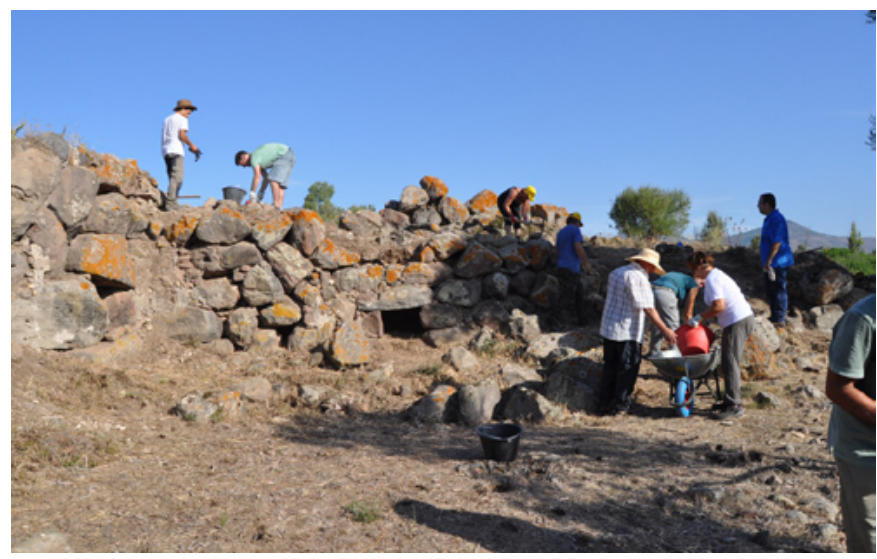

Proceso de excavación del nuraghe por los participantes | foto proyecto Nuraghe

El proyecto Nurhague plantea una nueva forma de trabajo que nos permita resolver aquellas cuestiones, principalmente de índole económica, que en estos momentos dificultan la gestión de los sitios arqueológicos, resaltando la figura del arqueólogo, no sólo como investigador, sino como gestor patrimonial.

Sin duda, la principal ventaja con la que cuenta esta propuesta es la implicación de diferentes asociaciones de la zona, que tienen como objetivo el estudio y puesta en valor del patrimonio local, demandando, a su vez, una participación activa en el proceso de recuperación del yacimiento.

La solución planteada fue ofrecer a la comunidad la oportunidad de acceder a su "alfabetización científica" en arqueología y patrimonio, a partir de su implicación en el proyecto integral de intervención. De este modo, pueden conocer directamente la problemática que implica la gestión de un sitio arqueológico desde la excavación hasta su puesta en valor e integración en circuitos culturales y turísticos. Nos alejamos así del tradicional proyecto arqueológico de raíz academicista, en el que la colectividad es una mera espectadora, incorporándola como actor principal en todas las fases del proceso.

La metodología de trabajo pretende compartir y poner al alcance de sus participantes las distintas tareas y trabajos que competen al mundo de la arqueología, además de incluir la asistencia a conferencias y visitas guiadas por expertos que les permitan conocer diferentes teorías, criterios y metodologías de trabajo, dotando al alumnado de las herramientas adecuadas para crear su propio pensamiento crítico, con el fin de limar las contemporáneas controversias socio-científicas existentes sobre el horizonte cultural de la civilización nurágica y la ciencia arqueológica.

Como alternativa a la tradicional financiación de la subvención pública, el proyecto se articula mediante campañas de intervención arqueológica anuales en las que se organiza un curso formativo abierto a todas las personas que quieran participar con independencia de su formación y procedencia. Todos los participantes, tanto foráneos como locales, realizan una aportación económica que sufraga parte del proyecto, recibiendo a cambio una formación patrimonial de calidad, que posibilita crear vínculos emocionales a través de las vivencias adquiridas y el contacto directo con el patrimonio.

La celebración del curso sirve además como dinamizador económico, social y cultural de la zona durante su ejecución y constituye un primer impulso para la futura puesta en valor del yacimiento.

El éxito de esta metodología se ha hecho patente desde los comienzos del proyecto. Los participantes comprendieron que cualquier acción no controlada que se realice sobre el patrimonio arqueológico puede suponer una pérdida irreversible y que la actividad investigadora debía ser controlada y supervisada por un equipo solvente, convirtiéndose ellos mismos en los principales valedores 
del yacimiento. Asimismo, en los intervalos en los que no ha habido intervención asumieron parte de las tareas de promoción y recaudación de fondos que garantizaran la viabilidad del proyecto: venta de calendarios, participación en convocatorias turísticas, celebración de jornadas de puertas abiertas, actividades para escolares, etc.

La movilización social generada por el proyecto ha propiciado la participación activa de la administración local, garantizando los medios técnicos y las infraestructuras necesarias para su desarrollo, y las empresas locales que, a modo de crowdfunding, y en vista de las posibilidades económicas a medio y largo plazo, han realizado aportaciones económicas que garantizan su sostenibilidad y los posiciona como colaboradores y mecenas ${ }^{3}$.

Siempre nos llama la atención las preguntas que nos hacen cuando hablamos del proyecto Nuraghe: ¿por qué Cerdeña? ¿por qué San Giovanni Suergiu? ¿por qué la civilización nurágica? Sin duda, es la ilusión que emana desde sus comienzos la principal respuesta.

\section{NOTAS}

1. www.comune.sangiovannisuergiu.ci.it

2. Para más información sobre los resultados de la primera campaña se puede consultar: http:// www.nationalgeographic.com.es/articulo/historia/ actualidad/10271/nuraghe_candelargiu_saldra_luz.html\# y www.artyhum.com/revista/14/\#/32

3. Más información sobre las modalidades de mecenazgo en www.proyectonuraghe.com/patrocinadores

\section{BIBLIOGRAFÍA}

- Álvarez, A. (2015) La difusión del patrimonio. Una obligación social. Revista PH [en línea], n. ${ }^{\circ} 87,2015$, pp. 218 $219<$ http://www.iaph.es/revistaph/index.php/revistaph/article/ view/3561> [Consulta: 5/07/2015]

- CAMERON, W.; CARR, N. (2013) Tourism and archaeology. Sustainable meeting grounds. Walnut Creek: Left Coast Press, 2013

- DíAZ, N.; RUT, M. (2012) Las controversias socio-científicas: temáticas e importancia para la educación científica. Revista Eureka sobre Enseñanza y divulgación de las ciencias, 9 (1), 2012, pp. $54-70$

- ESPAÑA, E.; PRIETO, T. (2010) Problemas sociocientíficos y enseñanza-aprendizaje de las ciencias. Investigación en la escuela [en línea] n. ${ }^{\circ} 71,2010$, pp. 17-24 <http://investigacionenlaescuela.es/articulos/71/R71_2.pdf> [Consulta: 6/07/2015]

- LILLIU, G. (1988) La civiltà dei Sardi dal paleolitico all'età dei nuraghi. Torino: Nuova ERI, 1988

- MUÑOZ, S. (2015) El patrimonio cultural y su mantenimiento en tiempos de crisis. Patrocinio, mecenazgo y crowfunding: ¿la solución? Revista $\mathrm{PH}$ [en línea], n. ${ }^{\circ} 87,2015$, pp. 5-7 <http:// www.iaph.es/revistaph/index.php/revistaph/article/view/3597> [Consulta: 5/07/2015]

- RODRíguez, O. (2013) In campis myrteis. Un proyecto para el análisis diacrónico del territorio de la región sulcitana: una primera aproximación metodológica al estudio de la época antigua. En L'Africa Romana. XX Convegno internazionale di estudi. Momenti di continuità e rottura: Bilancio di 30 anni di convegni de L'Africa Romana. Alghero 26-29 settembre 2013 (en prensa) 